\title{
History as a tool in orthopaedic education
}

\author{
Philippe Hernigou • Marko Pecina
}

Received: 12 January 2013 / Accepted: 21 January 2013 /Published online: 6 February 2013

(C) Springer-Verlag Berlin Heidelberg 2013

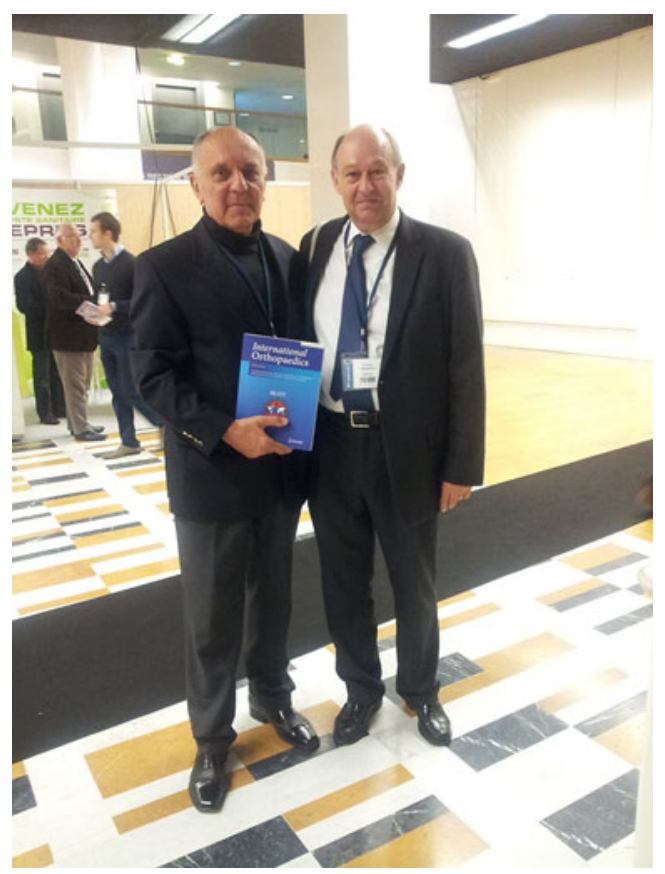

Fig. 1 Marko Pećina (with the journal International Orthopaedics) and Philippe Hernigou during the 87th SOFCOT Congress in Paris 2012

International Orthopaedics proposes to present an historical vignette with each journal. The idea is to offer one strategy for teaching orthopaedic surgery through various historical vignettes with original documents. Given a spectrum of different aims, historians, philosophers of science,

P. Hernigou $(\bowtie)$

Chirurgie Orthopedique, Hopital Henri Mondor, University Paris

East, Paris, France

e-mail: philippe.hernigou@hmn.aphp.fr

\section{Pecina}

School of Medicine, Department of Orthopaedic Surgery,

University of Zagreb, Zagreb, Croatia orthopaedic researchers and orthopaedic surgeons can contribute to the use of history to enhance teaching orthopaedic science.

Perhaps the most common use of history of medicine is to celebrate landmark discoveries and medical practitioners. On one level, this connects scientific knowledge — often viewed as objective and impersonal - to specific names, faces, times and places. Orthopaedic surgery thus gains a "human" dimension. When we laud a discovery in orthopaedic surgery, we indirectly convey on a deeper level a value in science itself and in novel ideas. For example, when we establish a relationship between M. Urist and bone morphogenetic protein (BMP), we thereby convey implicit standards for the introduction of growth factors in orthopaedic surgery. Such images can be adopted as goals, and an historical vignette on this scientist may potentially establish a "role model", and history may thus help broadly recruit more participants into science. But historians may also be concerned that an exclusive emphasis on "heroes" and dramatic discoveries may be misleading. Sometimes the role models we construct - of Ambroise Pare or Dupuytren, as "genius" or "superhuman"-may be biased portraits, and one challenge, then, is to make scientists seem "human" in scale, perhaps demystifying their achievements and openly recognising their flaws. We often find it convenient, for example, to credit single individuals, though achievements are rarely due to one person alone. Further, emphasising conceptual achievements rather than innovations in instrumentation or technology — or theoreticians rather than technicians or manufacturers - conveys a strong bias about the value of intellect versus labor. Plainly, we need to be more sensitive to the sometimes hidden lessons implicit in our explicit uses of history.

Discoveries may also be addressed in the context of conceptual development. That is, the history of the emergence of a concept or a family of concepts over many decades or even centuries, say, about plaster, external fixation, internal fixation, arthroplasties or genetics today, may 
structure and unify a series of lessons. The discussion of an individual discovery may become more fine-grained and highlight the reasoning or experimental process more closely. The temporal-developmental framework is another way to approach and structure of ideas and to see how the horizon of scientific inquiry changes.

The history of orthopaedic surgery is also valuable as a "how-story" of science. That is, it allows us to appreciate how concepts emerge: from confusion, ambiguity, surprise or deliberate probing, sometimes dramatically in sudden insights, sometimes gradually and with great difficulty. Through case studies or commentary, we can convey themes in the historical process of science. For example, one may introduce the role of serendipity or chance, and how, perhaps "chance favours only the prepared mind": a theme commonly associated with Röntgen's investigations of X-rays.

One of the messages we want to convey is that science and technology are activities conducted by and for real people. That is, research is motivated by sheer curiosity about the world around us and by efforts to improve the human condition, for example, the Kuntcher nail in Germany or Illizarov technique in Russia. We can convey relevance in many ways, but history allows us to recover the original contexts of invention or discovery. In addition, the fate of knowledge or technologies since their appearance may reveal how such relevance may either persist or change. Nor is scientific practice isolated from other human affairs. History is replete, of course, with fascinating or humorous anecdotes, whether about Smith Petersen discovering Vitallium with his dentist or Charnley discovering cement with his dental mechanical engineer. Such stories are simply entertaining and add texture to our stories about experimentation or reasoning processes.

The message about the human context of orthopaedic surgery can sometimes be extended to highlight its broader social dimensions. History provides examples of how scientific orthopaedic ideas have realigned cultural attitudes (hip dislocation in children according to the way of dressing babies), even world views, and how technologies have materially affected industry (polyethylene, metal on metal, ceramic for hip arthroplasties). Predominant social values have also entered science in the reverse direction, sometimes substantially promoting productive research, as in the absence of money leading to the concept of the Illizarov system. History shows how orthopaedic surgery and society are intertwined. It can also be fruitful simply to provide a social portrait of the period and place in which certain scientific ideas emerged and, sometimes, how science was regarded differently. In this way, for example, we learn how orthopaedic surgery in olden days was practiced differently in India, Africa, China, Asia or America from that in Egypt Greece or Renaissance Europe, and this phenomenon is still continuing today.

The direction of information flow or benefit, however, may not always be from those who study science to those who teach it. The specific needs of the science educational context may identify where information is incomplete, and thus where further work in history or science studies can be directly fruitful. The educational context may also suggest more actively new avenues of research. The context of appreciating conceptions may reawaken historical interest; for example, for Legg-Perthes-Calvé, who suggested the same classifications in different countries. The greatest challenge in transforming conventional histories for education may be in organising - or reorganising - material. First in the educational context, of course, is achieving an understanding of the concepts themselves. One may take as central, therefore, the historical origin of individual concepts. Single (even if complex) episodes can therefore serve as the critical focal points for elaborating the various contexts enumerated above. Episodic focus may be especially valuable for the organisation of several concepts (or episodes) along different thematic lines. One may follow a more conventional development of content, for example ("Orthopaedics through time"). One may equally elect to combine a group of episodes that develop a particular set of experimental skills, or that highlight a particular philosophical issuesay, the relation of orthopaedic progress and wars, or conceptions of realism. Technological achievements, too, may be documented as well as concepts.

As depicted in the parts above, orthopaedic vignettes may contain a number of elements. They may (and perhaps ideally should) include:

- the historical setting, including contemporary (local?) "news" events and pictures.

- cultural context(s) of discovery, especially where similar or overlapping concepts have emerged in different cultures, or where pervasive ideas in society have significantly shaped scientific thought

- accounts of original questions and contexts for research to situate any "discovery" in an ongoing practice and to revive uncertainties

- accounts of discovery, including experimental design and apparatus, skills, and reasoning patterns (both experimental and theoretical), possibly distributed among many members of a community

- for experimental simulations, the description of the technology: for example, the pendulum of Charnley

- biographical material on "significant" figures, highlighting entertaining or humorous anecdotes, motivations for research, and including a few images of perfection and imperfection

- for role-playing: portraits (young, old) and brief characterisations of the orthopaedic surgeon's personality and/or common gestures

- copies of original papers or documents (diaries, letters, notebooks) or excerpts from them; contemporary illustrations 
- $\quad$ simulation possibilities for historical dialogues, debates or symposia

- discussion of relevant issues about the nature of science, such as the roles of chance, prediction, styles of argument, or standards of evidence

- historical implications of the concept, both scientifically and socially

- bibliography of relevant films, videos and computer software

- true orthopaedic stories based on experience /practice

- history of orthopaedic journals
- book reviews of orthopaedic books dealing with discipline heritage

- experiences of practitioners who found the solution to a certain orthopaedic problem encountered in practice through the help of history/ using history, not only as a potent tool in teaching othopaedics, but as an motivating tool for innovation or solving a specific problem

Each orthopaedic surgeon is therefore asked to send a manuscript about history to the journal. 